\title{
CORRESPONDENCE
}

\section{WERNICKE'S PUPILLARY REACTION}

To the Editor of The British Journal of Ophthalmology

SIR,-I had not read Mr. Fisher's description of the manner of determining the presence or absence of Wernicke's pupillary reaction until yesterday. When I sent you my note on this reaction, I was unaware that I was describing a new or recent mode of procedure. I had heard that the late Sir Henry Swanzy was wont to place a patient sideways at a window when observing Wernicke's reaction. But my interest lay chiefly in the vitiating influence of ametropia of the eye under examination in this connection.

Dublin,

October 5, 1923.

Yours truly, J. D. Cummins.

\section{“OPTICAL BENEFIT" AND PANEL PRACTITIONERS}

To the Editor of The British Journal of Ophthalmology

SIR,-May I point out that insured persons applying to approved societies for optical benefit are being provided with forms for signature by the panel practitioner.

One form I have seen is a certificate that the patient is recommended "to consult an optician." By signing it the harassed practitioner is surely encouraging unqualified practice. Can you kindly bring this growing evil to the notice of your readers?

STOCKPORT, I am, yours faithfully,

October 20, 1923.

Garth ApThomas, M.D.

\section{CONGENITAL MIOSIS AND THE NORMAL MUSCULUS DILATATOR PUPILLAE}

To the Editor of The British Journal of Ophthalmology

SIR,-Will you allow me the following supplementary lines to the recent article by $\mathrm{O}$. Berner and myself on "Congenital Miosis or Pinhole Pupils owing to Developmental Faults of the Dilatator Muscle."

Before we began our work with the irides from patients with congenital miosis, Dr. Berner had microscopically examined the irides from 12 normal persons in different ages between 17 and 65 (depigmentation: Alfieri or hydrogen dioxide). In all cases the dilatator muscle was found well developed from the pupillary margin to the ciliary border. 